\title{
Effect of Zinc on NMDA Receptor-Mediated Channel Currents in Cortical Neurons
}

\author{
Chadwick W. Christine and Dennis W. Choi \\ Department of Neurology, Stanford University Medical Center, Stanford, California 94305
}

Recent data have indicated that the divalent cation $\mathrm{Zn}^{2+}$ can selectively block central neuronal excitation mediated by $\mathrm{N}$-methyl-D-aspartate (NMDA) receptors. The present experiments were conducted to determine the action of $\mathrm{Zn}^{2+}$ at the single-channel level. Outside-out membrane patches were prepared from cultured murine cortical neurons. Glutamate, $3 \mu \mathrm{M}$, in the presence of $5 \mu \mathrm{M}$ glycine activated channels with a main conductance state of about $50 \mathrm{pS}$ which were blocked in a voltage-dependent manner by $\mathbf{M g}^{2+} . \mathbf{Z n}^{2+}$ appeared to have 2 effects on these NMDA receptor-activated channels. First, at concentrations as low as 1-10 $\mu \mathrm{M}$, $\mathrm{Zn}^{2+}$ produced a concentration-dependent reduction in channel open probability, insensitive to membrane voltage between -60 and $+40 \mathrm{mV}$; about $50 \%$ reduction in open probability was produced by $3 \mu \mathrm{M} Z n^{2+}$. This reduction was mostly due to a decrease in opening frequency and only weakly mimicked by $\mathrm{Mg}^{2+}$. Second, at higher concentrations (10$100 \mu \mathrm{M}$ ) and negative membrane voltages, $\mathrm{Zn}^{2+}$ additionally produced an apparent reduction in single-channel amplitude, associated with an increase in channel noise, suggestive of a fast channel block. The amplitude reduction was voltage-dependent, with a $\delta$ of 0.51 ; amplitude distribution analysis suggested that this voltage dependence was primarily contributed by the "on" blocking rate constant, with little contribution from the "off" rate constant. The channel block produced by $\mathrm{Zn}^{2+}$ was faster than that of $\mathbf{M g}^{2+}$, which at $100 \mu \mathrm{M}$ and negative membrane voltages induces flickering of the NMDA receptor-activated channel without changing apparent channel amplitude.

Thus, $\mathbf{Z n}^{2+}$ may reduce NMDA receptor-activated channel currents on cortical neurons by acting at 2 different sites, one outside the membrane field and affecting opening frequency, and the other inside the channel and interfering directly with the passage of ions. In this manner, $\mathrm{Zn}^{2+} \mathrm{CO}-$ released with glutamate from presynaptic terminals may dynamically modulate NMDA receptor-activated currents.

The mammalian CNS contains large amounts of chelatable $\mathrm{ZN}^{2+}$ (Maske, 1955; Frederickson et al., 1983; Danscher et al., 1985). Much of this $\mathrm{Zn}^{2+}$ is localized to synaptic vesicles in

\footnotetext{
Received Apr. 3, 1989; revised June 19, 1989; accepted June 20, 1989.

We thank $O$. Andersen and $J$. Koh for helpful discussions, and $R$. Aldrich for both helpful discussions and comments on the manuscript. We also thank K. Rose for expert assistance with cell cultures. This research was supported by NIH grants NS1215l and NS26907.

Correspondence should be addressed to Dennis W. Choi, Department of Neurology, C-338, Stanford University Medical Center, Stanford, CA 94305.

Copyright (C) 1990 Society for Neuroscience $0270-6474 / 90 / 010108-09 \$ 02.00 / 0$
}

excitatory boutons throughout the telencephalon and is likely released into the synaptic cleft during excitation (Assaf and Chung, 1984; Howell et al., 1984), especially at higher rates of neuronal firing (Aniksztejn et al., 1987). The extracellular accumulation of synaptically released $\mathrm{Zn}^{2+}$ may be substantial. Assaf and Chung (1984) found that exposure to high $\mathrm{K}^{+}$induced the release of $18 \%$ of the $\mathrm{Zn}^{2+}$ contained in rat hippocampal slices, an amount of $\mathrm{Zn}^{2+}$ that distributed evenly in tissue extracellular space would produce a concentration of $300 \mu \mathrm{M}$.

Based on the observations that $\mathrm{Zn}^{2+}$ selectively attenuates the neuroexcitatory and neurotoxic effects of $N$-methyl-D-aspartate (NMDA) receptor agonists on cortical neurons, while slightly increasing the effects of AMPA or quisqualate (Peters et al., 1987), we proposed that $\mathrm{Zn}^{2+}$ might be an important endogenous modulator of the postsynaptic response to co-released transmitter glutamate. A similar conclusion was reached independently by Westbrook and Mayer (1987), who found that $\mathrm{Zn}^{2+}$ could noncompetitively reduce NMDA-evoked currents in hippocampal neurons. In addition, Forsythe et al. (1988) showed than $\mathrm{Zn}^{2+}$ could block slow NMDA receptor-mediated excitatory postsynaptic potentials in hippocampal neurons.

The mechanisms by which $\mathrm{Zn}^{2+}$ might produce this physiologically relevant antagonism of NMDA receptor activation has not yet been defined. Another divalent cation, $\mathrm{Mg}^{2+}$, has been established to produce voltage-dependent brief interruptions (flickering) of current through the NMDA receptor-linked channel (Nowak et al., 1984; Ascher and Nowak, 1988). The simple possibility that $\mathrm{Zn}^{2+}$ might act exactly like $\mathrm{Mg}^{2+}$ seems not to be the case, as $\mathrm{Zn}^{2+}$ antagonism of cellular NMDA responses appears to show less voltage dependence (Peters et al., 1987; Westbrook and Mayer, 1987). The purpose of the present study was to investigate the nature of $\mathrm{Zn}^{2+}$ antagonism at the singlechannel level. Abstracts have appeared (Christine and Choi, 1988, 1989).

\section{Materials and Methods}

Cortical cell culture. Mixed cortical cell cultures, containing both neuronal and glial elements, were prepared as previously described (Choi et al., 1987) from fetal mice at 14-18 d gestation. Dissociated cortical cells were plated in Primaria (Falcon) $35 \mathrm{~mm}$ dishes $\left(10^{\circ}\right.$ cells/dish) in Eagle's minimal essential medium (MEM-Earle's salts, supplied glutamine-free) supplemented with $10 \%$ heat-inactivated horse serum, $10 \%$ fetal bovine serum, glutamine ( $2 \mathrm{~mm}$ ), and glucose (total, $21 \mathrm{~mm}$ ). Cultures were kept at $37^{\circ} \mathrm{C}$ in a humidified $\mathrm{CO}_{2}$-containing atmosphere. After 5-12 din vitro, non-neuronal cell division was halted by exposure to $10^{-5} \mathrm{M}$ cytosine arabinoside, and the cells were shifted into a maintenance medium identical to the plating media, but lacking fetal serum. Subsequent media replacement was carried out twice per week. Cultures from 8-20 din vitro were used.

Patch-clamp methods. Patch pipettes were pulled from borosilicate glass tubing in 3 or 4 stages using a Sutter Instrument P-80 puller. Pipette 
resistance was 8-15 $\mathrm{m} \Omega$ when filled with the below pipette solution and placed in the bath. A silver-silver chloride wire was used as the electrode within the patch pipette and, through an agar/saline bridge, as the bath ground. A List EPC-7 patch-clamp amplifier with a $10 \mathrm{kHz}$ filter setting was used to measure membrane currents and control transmembrane potential. The electrode balancing circuit of the amplifier was adjusted to give zero current just prior to each experiment and was routinely checked after a patch had been lost. Offset potentials after an experiment seldom exceeded $1 \mathrm{mV}$.

Recordings were made at room temperature using the outside-out patch configuration (Hamill et al., 1981). Only stable recordings lacking spontaneous channel activity were studied. Patch current and pipette potential were recorded continuously and stored on magnetic tape for subsequent analysis. Patch seal resistance was determined by measuring the change in membrane current when holding potential was changed (usually in $10 \mathrm{mV}$ steps).

Solutions. The patch pipette was filled with an "intracellular" solution containing (in mM) $140 \mathrm{CsCl}, 4 \mathrm{NaCl}, 0.5 \mathrm{CaCl}_{2}, 5$ EGTA $(\mathrm{pCa} \approx 7.3$ ), and 10 HEPES. Prior to an experiment, the maintenance medium was rinsed from the culture dish and replaced by a defined solution containing (in $\mathrm{mm}$ ): $140 \mathrm{NaCl}, 2.8 \mathrm{KCl}, 1 \mathrm{CaCl}_{2}, 10 \mathrm{HEPES}$, and 5 glucose. The $\mathrm{pH}$ of all solutions was adjusted to 7.3 using $\mathrm{NaOH}$ (final pipette $\left[\mathrm{Na}^{+}\right]=18 \mathrm{~mm}$; final extracellular $\left[\mathrm{Na}^{+}\right]=146.6 \mathrm{~mm}$ ).

After an outside-out patch was obtained, the pipette tip was inserted into a constant-flow fluid-exchange pipette (Yellen, 1982) mounted distal to a rotary valve allowing rapid selection of experimental perfusion solutions. Full replacement of solution from the dead space between the valve and the exchange pipette took approximately $30 \mathrm{sec}$ (this was confirmed with junction potential shifts after a change to solution with a reduced salt concentration). All experimental solutions were composed of the bathing solution (see above) plus $5 \mu \mathrm{m}$ glycine to increase the opening of NMDA receptor-activated channels (Johnson and Ascher, 1987); glucose was omitted. Most experimental solutions also contained $3 \mu \mathrm{M}$ glutamate, along with the desired concentration of either $\mathrm{Zn}^{2+}$ or $\mathrm{Mg}^{2+}$. Glutamate was the selected agonist for the NMDA receptor because its dissociation constant with divalent cations is known. Glutamate and glycine concentrations were increased when $\mathrm{Zn}^{2+}$ was present in excess of $1 \mu \mathrm{M}$ to correct for their complexing (Perrin, 1986) and maintain free concentrations of 3 and $5 \mu \mathrm{M}$, respectively. For example,

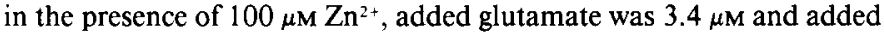
glycine was $5.3 \mu \mathrm{M}$.

Single-channel analysis. Data selected for analysis was played back from magnetic tape and converted to digital format. In general, recordings with frequent double-channel openings or substate transitions were excluded from quantitative analysis; thus, analysis was based largely on patches with only a single active channel. Patch current was normally filtered at $1-2 \mathrm{kHz}$. ( $-3 \mathrm{~dB}$ corner frequency, 8-pole Bessel) and digitally sampled at 5 times the filtering frequency.

Two types of amplitude histograms were constructed. The first type, representing mean channel amplitudes, was based on analysis by a commercially available software package (P-Clamp 4.0, Axon Instruments). Mean amplitude values were calculated for each event that exceeded a threshold of one-half the average channel amplitude. Events shorter than 2 msec were considered to be attenuated by the high-frequency filter and hence not included in these mean amplitude histograms, but they were included in dwell-time analysis. Care was taken to reset the baseline when shifts occurred.

A second type of amplitude histogram was constructed for rate-constant analysis of the channel flicker. A routine written in PASCAL was used to construct point by point amplitude histograms directly from digitized current records. These histograms therefore reflected the full range of channel activity, rather than the means of defined events.

In the 2-state fast channel block model (Neher and Steinbach, 1978), an open channel alternates rapidly between an open and blocked state, with the block "off" rate, $\alpha$, and the "on" rate, $\beta$.

$$
\begin{aligned}
R^{*}+\mathrm{Zn} \stackrel{\rho}{\rightleftharpoons} R^{*}-\mathrm{Zn} \\
\text { (open channel) }
\end{aligned}
$$

If channel current is filtered with a first-order filter of time constant tau ( $\tau$ ), FitzHugh (1983) and Yellen (1984) have demonstrated that the amplitude distribution will be a $\beta$-distribution with the probability density function

$$
f(y)=y^{(a-1)}(1-y)^{(h-1) / B(a, b)}
$$

where $a=\alpha \tau$ and $b=\beta \tau$ and

$$
B(a, b)=\int_{0}^{1} y^{(a-1)}(1-y)^{(h-1)} d y
$$

Since practical filters are not first order, an empirical conversion for an 8-pole Bessel filter is given by Yellen (1984) as $\tau=0.228 / f$, where $\tau$ is the time constant of the equivalent single-pole filter. We found that filtering at $1 \mathrm{kHz}$ provided the best resolution of the amplitude distribution, yielding $\tau=228 \mu \mathrm{sec}$.

For this analysis we formed histograms of current amplitude from portions of experiments selected for a single active channel with no substate activity along with some baseline current. Care was taken to avoid data with a changing baseline. A Gaussian curve was fitted to the peak corresponding to the baseline and was subtracted from the histogram to remove the closed channel contribution; this procedure produced little change in the histogram fits since analysis was not attempted when the baseline overlapped the open channel level. The mean of the Gaussian fit was used as the zero-amplitude bin of the amplitude histogram; in each experiment, histograms were normalized to full channel amplitude obtained when no blocking ion was present.

Computer-generated $\beta$-distributions were fitted by eye to each normalized amplitude histogram by adjusting the 2 parameters $a$ and $b$. The fit was quite sensitive to small changes in both parameters, so optimization to within 0.3 generally involved little ambiguity. In order to compensate for the broadening of the experimental distribution by unrelated noise, the theoretical distribution was also broadened by convolving it with the Gaussian used to fit the baseline.

Dwell times were determined using a half-amplitude definition of transitions. Three measurements were determined from the dwcll-timc analysis: the open probability $\left(P_{\mathrm{o}}\right)$, the frequency of opening $\left(f_{\mathrm{o}}\right)$, and mean channel open time $\left(\tau_{0}\right)$. To compare data from different experiments, we scaled raw values of $f_{\mathrm{o}}$ and $P_{\mathrm{o}}$ with a control period when no $\mathrm{Zn}^{2+}$ or $\mathrm{Mg}^{2+}$ was present. Open probability and opening frequency were then expressed as a percentage of this control period.

Open time histograms were constructed from dwell-time analysis, and these were fitted with single- and double-exponential fits to determine the mean channel open time. In all cases, the first bin was ignored in the fitting process. While some experiments required a double exponential for a good fit $\left(\tau_{1} \approx 1-2 \mathrm{msec}, \tau, \approx 9-10 \mathrm{msec}\right.$ (see Jahr and Stevens, 1987; Ascher et al., 1988), we found that most were adequately fitted with a single exponential $(\tau \approx 5 \mathrm{msec})$. We used the values of single-exponential fits to compare different experimental conditions.

Drugs and reagents. Glutamatc and glycinc werc purchased from Sigma. $\mathrm{ZnCl}_{2}$ and $\mathrm{MgCl}_{2}$ were analyzed reagent grade from Baker.

\section{Results}

Recordings were obtained from outside-out patches that showed no spontaneous channel activity. Perfusion of these patches with the "extracellular" solution plus $5 \mu \mathrm{M}$ glycine alone did not activate channels, but the addition of $3 \mu \mathrm{M}$ glutamate to the perfusate often elicited prominent channel activity (Figs. 1, 2). These channels had a main conductance state of about $50 \mathrm{pS}$, with infrequent transitions to subconductance states ranging from 15 to $50 \mathrm{pS}$. Most recordings did not have frequent substate activity, and those which did were excluded from quantitative analysis. Based on activation by $3 \mu \mathrm{M}$ glutamate, sensitivity to $\mathrm{Mg}^{2+}$ block, mean channel open time, and $I-V$ relationship (see below), these channels can be clearly identified as linked to the NMDA receptor.

Figure $1 A$ shows the overall qualitative effect of $\mathrm{Zn}^{2+}$ on these NMDA channels at a holding potential of $-50 \mathrm{mV} . \mathrm{Zn}^{2+}, 10$ $\mu \mathrm{M}$, produced a clear-cut reduction in the number of channel openings; $100 \mu \mathrm{M} 7 \mathrm{n}^{2+}$ reduced channel amplitude as well (Fig. $1 A$ ). Both of these effects were reversible. In addition, $\mathrm{Zn}^{2+}$ application was reproducibly associated with an upward shift in the patch current baseline, reflecting an increase in patch resistance. The magnitude of this increase varied among different patches; in a given patch, it increased with membrane hy- 
Figure 1. $\mathrm{Zn}^{2+}$ curtails NMDA channel activity. $A$, Pen writer traces of activity elicited by $3 \mu \mathrm{M}$ glutamate in a patch containing multiple active channels. Arrows mark changes in perfusion solutions; some mixing of solutions is inevitable and is most apparent during the washout period with control solution. Membrane potential $=-50 \mathrm{mV}$; channcl openings are downward. Addition of $\mathrm{Zn}^{2+}$ caused an increase in apparent seal resistance; values were 7.1

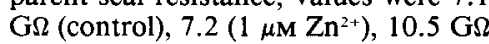
$\left(10 \mu \mathrm{M} \mathrm{Zn}^{2+}\right), 65 \mathrm{G} \Omega\left(100 \mu \mathrm{M} \mathrm{Zn}^{2+}\right)$, and $6.5 \mathrm{G} \Omega$ (second control). $B$, In this experiment, divalent cations increased seal resistance from $3.0 \mathrm{G} \Omega$ (control) to 8.9 $\mathrm{G} \Omega\left(10 \mu \mathrm{M} \mathrm{Zn}^{2+}\right)$ and $3.4 \mathrm{G} \Omega(10 \mu \mathrm{M}$ $\left.\mathrm{Mg}^{2+}\right) . \mathrm{Zn}^{2+}$ was more effective in reducing opening frequency than $\mathrm{Mg}^{2+}$; membrane potential $=-50 \mathrm{mV}$, same time and current scale as in $A$.
A Control $\downarrow 1 \mu \mathrm{M} \mathrm{Zn} \downarrow 10 \mu \mathrm{M} \mathrm{Zn} \quad \downarrow 100 \mu \mathrm{M} \mathrm{Zn} \downarrow$ Control

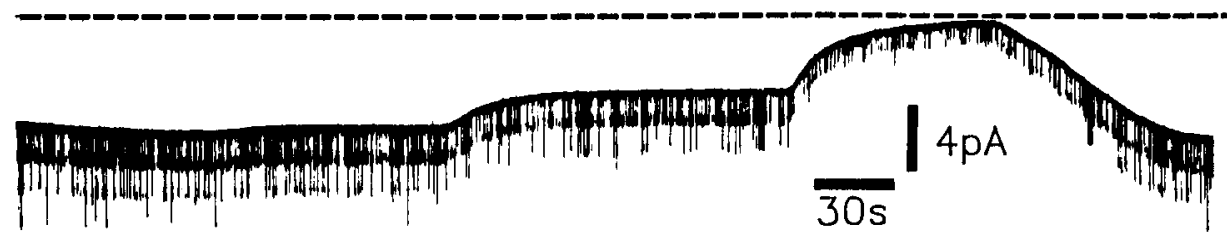

B perpolarization and raised $\mathrm{Zn}^{2+}$ concentrations. For example,

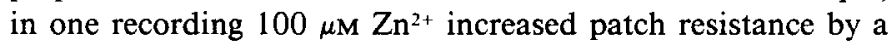
factor of 4.5 at a holding potential of $-60 \mathrm{mV}$, but only a factor of $1.2 \mathrm{at}+30 \mathrm{mV}$. This action of $\mathrm{Zn}^{2+}$ did not depend upon the presence of active NMDA channels in the patch. $\mathrm{Mg}^{2+}$ at similar concentrations did not have such a pronounced effect on patch resistance (Fig. 1B).

Further examination of the effect of $\mathrm{Zn}^{2+}$ on channel amplitude revealed that increasing $\mathrm{Zn}^{2+}$ over the range $1-100 \mu \mathrm{M}$ produced a graded reduction in apparent mean single-channel amplitude, associated with an increase in open-channel noise (Figs. 2, 3). In comparison, $100 \mu \mathrm{M} \mathrm{Mg}{ }^{2+}$ at negative membrane potentials produced resolvable flickering between the full open and the closed states (Fig. $3 A$ ). Neither $\mathrm{Zn}^{2+}$ nor $\mathrm{Mg}^{2+}$ had an effect on channel amplitude or mean channel open time at pos- itive holding potentials (Figs. $3 B, 4 A$ ), although both of these divalent cations did reduce opening frequency at all tested membrane potentials (see below).

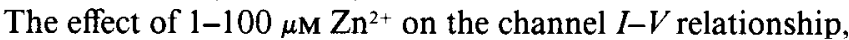
constructed from amplitude histograms, is shown in Figure 4A. At $\mathrm{Zn}^{2+}$ concentrations greater than $10 \mu \mathrm{M}$ and holding potentials below $-50 \mathrm{mV}$, channel amplitude leveled off consistent with a voltage-dependent block. Unfortunately, membrane potentials more negative than $-80 \mathrm{mV}$ were poorly tolerated by patch membranes. It was thus not possible to determine whether the $\mathrm{Zn}^{2+}$ block could be relieved with strong hyperpolarization as has been reported with other divalent cations, most notably $\mathrm{Mg}^{2+}$ (Mayer and Westbrook, 1987).

Of note, the $I-V$ curves did not pass through the origin but instead inverted at about $-6 \mathrm{mV}$. Part of this offset was likely
Figure 2. $\mathrm{Zn}^{2+}$ reduces single-channel amplitude in a concentration-dependent manner. These data, all from the same patch, were elicited by application of $3 \mu \mathrm{M}$ glutamate; membrane potential $=-60 \mathrm{mV}$ and openings are downward. Panel $A$ shows sample traces, while panel $B$ shows the corresponding amplitude histograms. Histograms represent the frequency of specified mean channel amplitude (see Materials and Methods); the bin width was $0.1 \mathrm{pA}$. The first trace shows a control record (no $\mathrm{Zn}^{2+}$ ). In subsequent traces and their corresponding histograms, increasing concentrations of $\mathrm{Zn}^{2+}(10,50$, and $100 \mu \mathrm{M}$ ) were included in the experimental solution. Data were filtered at $2 \mathrm{kHz}$ and sampled at $10 \mathrm{kHz}$ both for display in $A$ and for analysis in $B$.
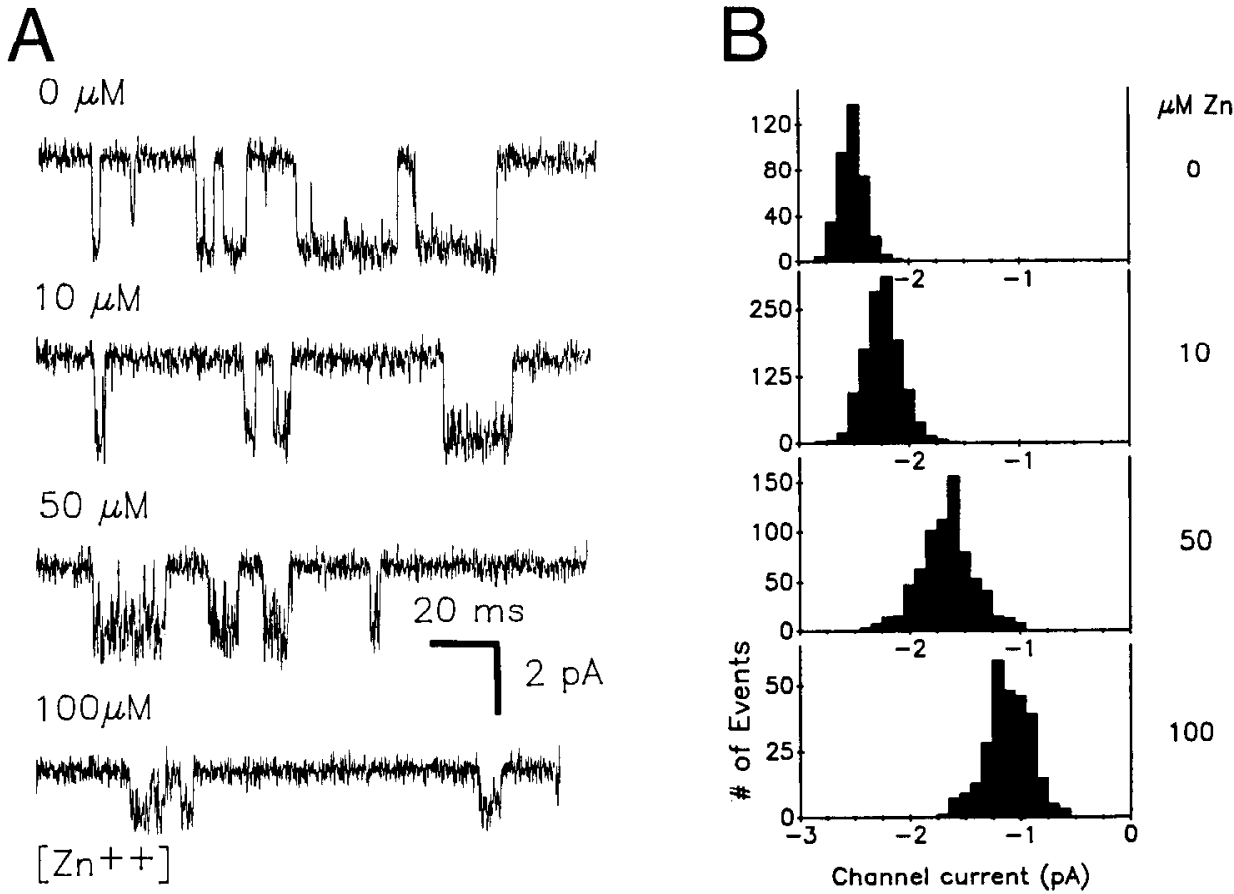
A
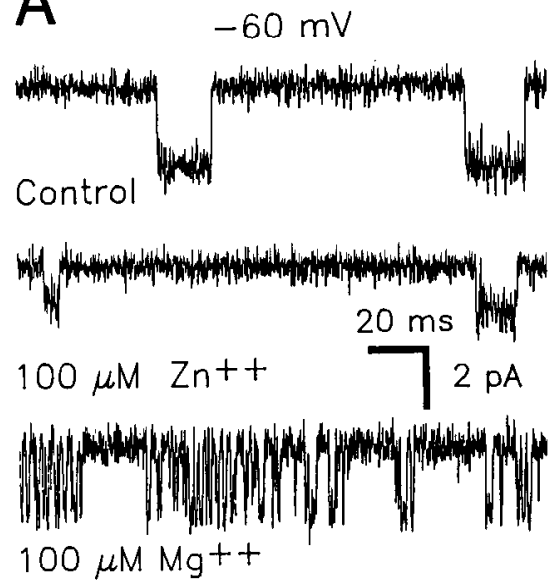

$100 \mu \mathrm{M} \mathrm{Mg}++$
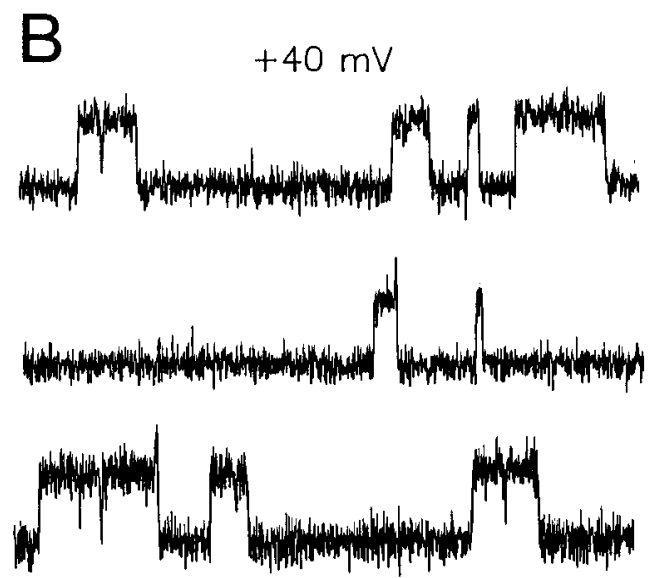

Figure 3. $\mathrm{Zn}^{2+}$ block is voltage-dependent but qualitatively different from $\mathrm{Mg}^{2+}$ block. Activity from a single patch perfused with $3 \mu \mathrm{M}$ glutamate without (control) or with the indicated divalent cations. $A$, Traces obtained at $-60 \mathrm{mV}$; $B$, traces obtained at $+40 \mathrm{mV}$. The $\mathrm{Zn}^{2+}$ and $\mathrm{Mg}^{2+}$ traces at $+40 \mathrm{mV}$ reveal a second active channel. Data was filtered at $2 \mathrm{kHz}$ and sampled at $10 \mathrm{kHz}$.
A

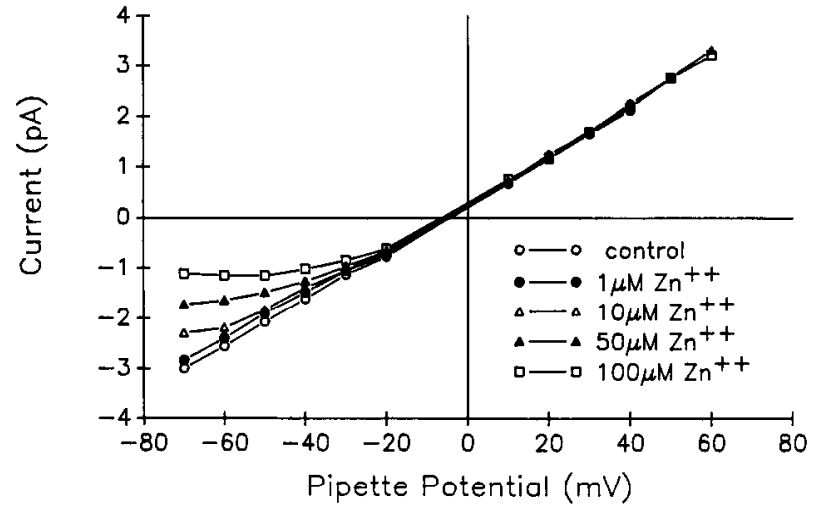

B

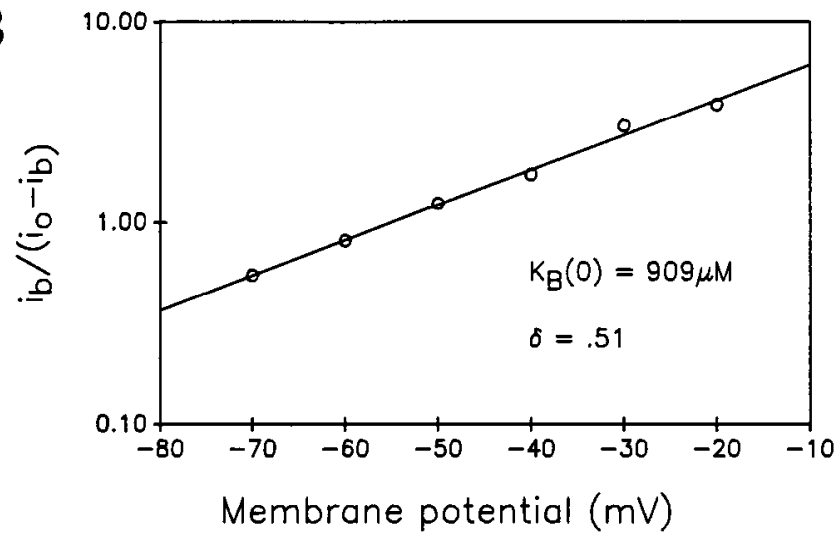

Figure 4. $\mathrm{Zn}^{2+}$ reduces single-channel amplitude in a voltage-dependent manner. $A$, Current-voltage relations of NMDA channels in experimental solutions containing different concentrations of $\mathrm{Zn}^{2+}$. Results from different experiments have been pooled for $100 \mu \mathrm{M} \mathrm{Zn}^{2+}(n=4)$,

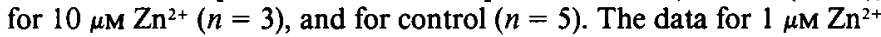
and $50 \mu \mathrm{M} \mathrm{Zn}^{2+}$ are from single experiments. $B$, Data from above are plotted as $i_{B} /\left(i_{0}-i_{B}\right)$ using points at $100 \mu \mathrm{M} \mathrm{Zn}^{2+}$ as $i_{b}$. The line denotes the fit of equation 1 (see text) to the data: $K_{d}(0)=909 \mu \mathrm{M}$ and $\delta=0.51$ \pm 0.014 .
A

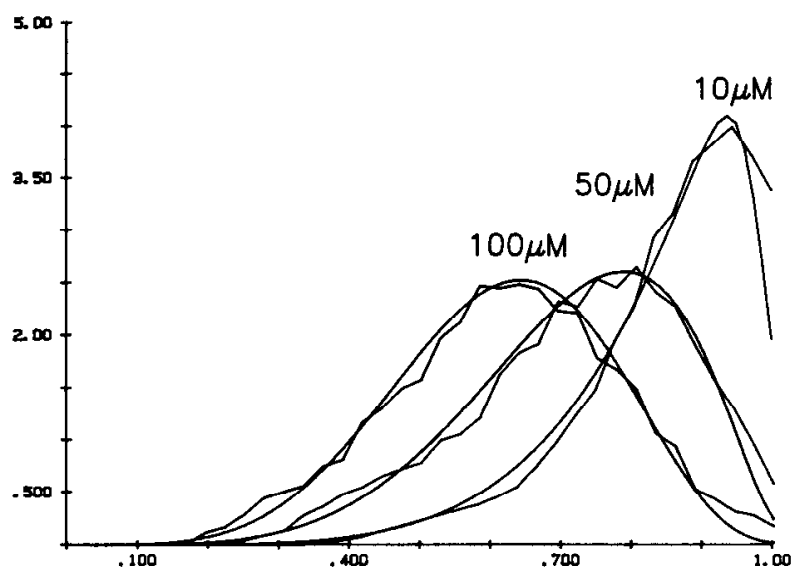

B

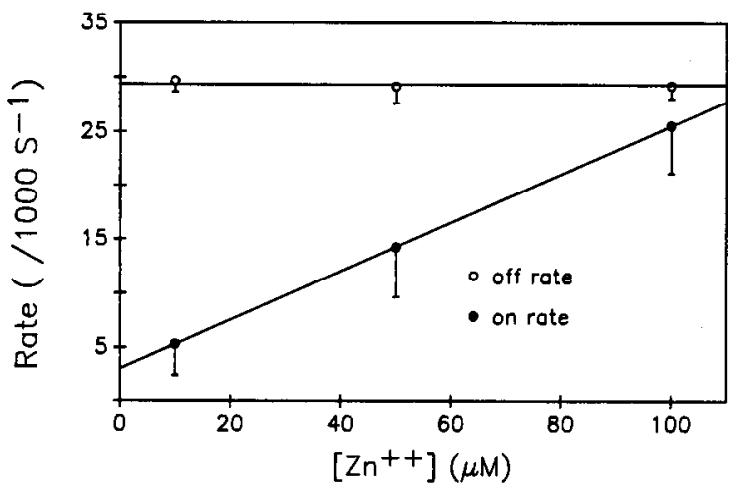

Figure 5. $\mathrm{Zn}^{2+}$ concentration dependence of blocking rates. $A, \mathrm{Ex}-$ amples of $\beta$-distribution fits to full data amplitude histograms. Proceeding from right to left, $\left[\mathrm{Zn}^{2+}\right]$ increases as indicated. Increasing $\left[\mathrm{Zn}^{2+}\right]$ shifted the amplitude distribution toward zero, and the fits reflect this shift as an increase on the on rate; the off rates were relatively unaffected. Values for the on rates at 10,50 and $100 \mu \mathrm{M} \mathrm{Zn}{ }^{2+}$ are $5.0 \times 10^{3}, 1.0 \times$ $10^{4}$, and $1.7 \times 10^{4} \mathrm{sec}^{-1}$; for the off rates they are $2.7 \times 10^{4}, 2.6 \times 10^{4}$, and $2.7 \times 10^{4} \mathrm{sec}^{-1}$. Bin width was $0.06 \mathrm{pA}$; membrane potential $=$ $-50 \mathrm{mV}$. $B$, Concentration dependence of blocking rates. The on and off rates are plotted as a function of $\left[\mathrm{Zn}^{2+}\right]$. Points represent means ( \pm SEM) of 3 experiments. The line plotted through the on rate constants has a slope of $2.25 \times 10^{6} \mathrm{M}^{-1} \mathrm{sec}^{-1}$; the line represents the mean value $\left(2.9 \times 10^{4} \mathrm{sec}^{-1}\right)$. 
A

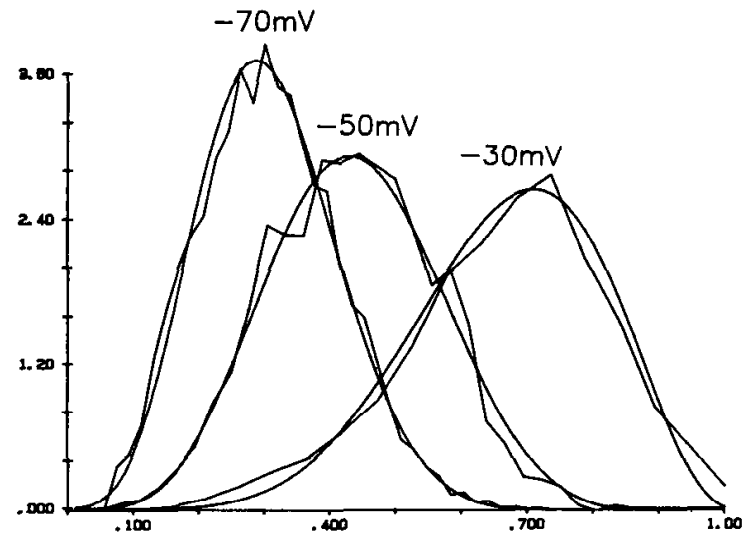

B

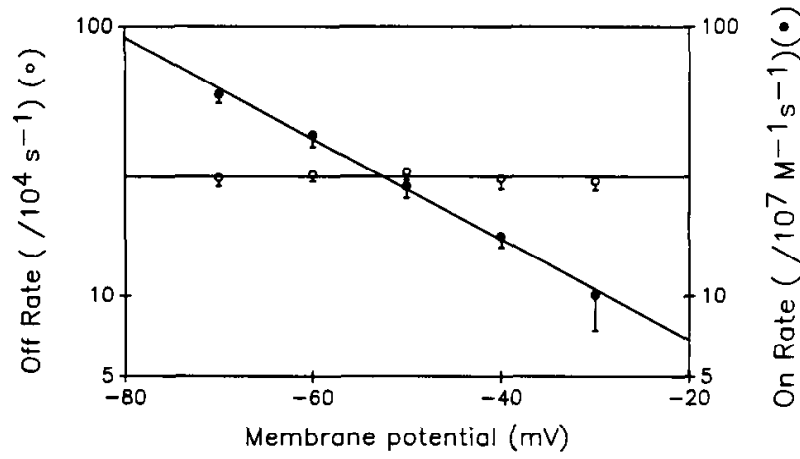

Figure 6. Voltage-dependence of blocking rate constants. $A, \beta$-distribution fits at indicated membrane potentials. In this experiment, $\left[\mathrm{Zn}^{2+}\right]$ was held constant at $100 \mu \mathrm{M}$ and the membrane potential varied from -30 to $-70 \mathrm{mV}$. As the membrane is hyperpolarized, the amplitude distribution shifts toward zero, reflecting an increase in the on rate but not the off rate. Values for the on rates at $-30,-50$, and $-70 \mathrm{mV}$ are $1.5 \times 10^{4}, 3.5 \times 10^{4}$, and $5.9 \times 10^{4}$; for the off rates, they are $2.9 \times$ $10^{4}, 2.7 \times 10^{4}$, and $2.7 \times 10^{4}$. Bin width was $0.06 \mathrm{pA}$ at each voltage. $B$, Voltage dependence of blocking rate constants. On and off rate constants are plotted as a function of membrane potential. Points represent the mean $( \pm$ SEM) of fits from 5 experiments. Linear regression of the on rate constants yields a line corresponding to $\delta=0.54$. The line drawn through the off rate constant points is horizontal and represents the mean value over the voltage range $\left(2.78 \times 10^{4} \mathrm{sec}^{-1}\right)$. A plot of the ratio off rate constant/on rate constant $\left(=K_{d}\right)$ yields a similar slope and yields a value of $990 \mu \mathrm{M}$ for $K_{d}$ at $0 \mathrm{mV}$. The $\mathrm{Zn}^{2+}$ concentration was $100 \mu \mathrm{M}$.

due to the slightly higher activity of monovalent ions in the patch pipette vs the bath (119.7 vs $113.9 \mathrm{mM})$, which would account for a $-1.3 \mathrm{mV}$ offset if $\mathrm{Cs}^{+}$and $\mathrm{Na}^{+}$permeate the channel cqually well. The balance of the offset may indicate a slightly greater permeability to $\mathrm{Cs}^{+}$over $\mathrm{Na}^{+}$. Such an offset in the $I-V$ relationship has been noted previously (Cull-Candy and Usowicz, 1987).

The voltage dependence of the $\mathrm{Zn}^{2+}$ block could be described using the relation (Woodhull, 1973)

$$
i_{B} /\left(i_{\mathrm{o}}-i_{B}\right)=\left\{K_{d}(0) /[B]\right\} \exp (\mathrm{z} \delta V e / k T),
$$

where $i_{B}$ is the channel current in the presence of the blocker, $i_{o}$ is the current in the absence of blocker, $K_{a}(0)$ is the dissociation constant for the blocker at $0 \mathrm{mV},[B]$ is the concentration of the blocking ion, $z$ is its valence, $\delta$ is the fraction of the membrane potential that is affecting block, $V$ is the membrane potential difference, $e$ is the elementary charge, $k$ is Boltzmann's constant, and $T$ is the temperature in Kelvin. At $100 \mu \mathrm{M} \mathrm{Zn}^{2+}$,

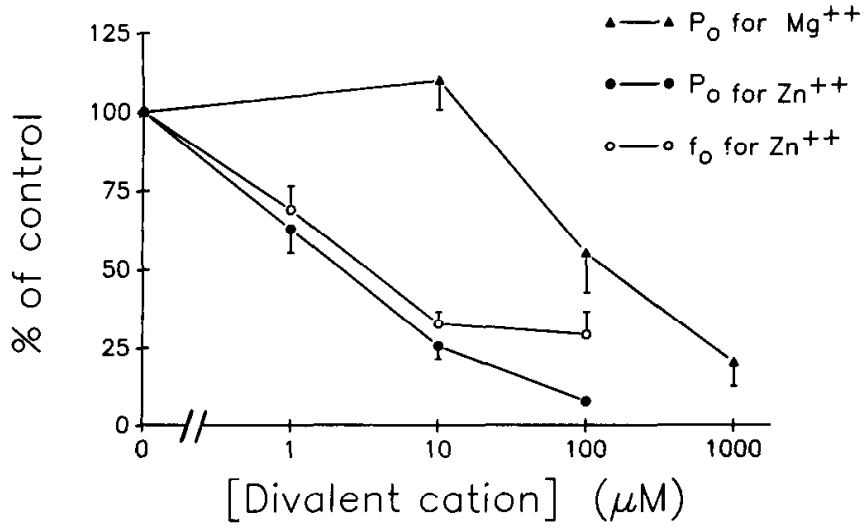

Figure 7. Effect of $\mathrm{Zn}^{2+}$ and $\mathrm{Mg}^{2+}$ on open probability and opening frequency. Open probability and opening frequency at $-50 \mathrm{mV}$ is plotted as a function of divalent cation concentration. All data points represent the mean values from 4-6 experiments $( \pm S E M)$.

this equation yielded values of 0.51 for $\delta$ and $909 \mu \mathrm{M}$ for $K_{d}(0)$ (Fig. 4B).

The most likely explanation for the observed voltage-dependent effect of $\mathrm{Zn}^{2+}$ on channel amplitude is that it produced a flicker block qualitatively similar to that produced by $\mathrm{Mg}^{2+}$, but much faster. Frequent brief interruptions of channel current too rapid to be resolved as individual events would lead to an apparent reduction in the level of open-channel current and would account for the observed increased noise in this current. Such a poorly resolved rapid flickering block has been shown to characterize the block of the $\mathrm{Ca}^{2+}$-activated $\mathrm{K}^{+}$channel by $\mathrm{Cs}^{+}$(Yellen, 1984), and may also characterize the block of the NMDA channel by $\mathrm{Mn}^{2+}$ (Ascher and Nowak, 1988).

Attempts to resolve $\mathrm{Zn}^{2+}$ flickering by raising the high-frequency filter cutoff to $2 \mathrm{kHz}$ were unsuccessful; higher settings were deemed unsatisfactory due to excessive high-frequency artifact noise. As an alternative test of the flicker hypothesis (and a method for estimating block on and off rates), we analyzed amplitude histograms of channel currents in the presence of $\mathrm{Zn}^{2+}$ according to a simple model of open-channel block (see Materials and Methods, as well as Neher and Steinbach, 1978; Yellen, 1984). In this model, the forward reaction rate, $\beta$, depends on the concentration of $\mathrm{Zn}^{2+}$, while the rate of unblocking, $\alpha$, is independent of $\mathrm{Zn}^{2+}$ concentration. Such a mechanism has been proposed for the block by $\mathrm{Mg}^{2+}$ of the NMDA receptoractivated channel (Ascher and Nowak, 1988).

Increasing $\mathrm{Zn}^{2+}$ concentration from 10 to $100 \mu \mathrm{M}$ at a constant holding potential of $-50 \mathrm{mV}$ produced a progressive shift in the channel amplitude histograms toward smaller values; these histograms could be closely approximated by theoretical $\beta$-distributions convoluted with baseline noise (Fig. $5 A$ ). Resultant calculated values for the block on rate increased linearly from $5.0 \times 10^{3}$ to $1.7 \times 10^{4} \mathrm{sec}^{-1}$ with increasing $\mathrm{Zn}^{2+}$ concentration (Fig. $5 B$ ). In contrast, the block off rate remained nearly constant at $2.7 \times 10^{4} \mathrm{sec}^{-1}$ with changing $\mathrm{Zn}^{2+}$ concentration (Fig. $5 B$ ). The finding that only the on rate was dependent on $\mathrm{Zn}^{2+}$ concentration is thus consistent with the simple blocking scheme mentioned above.

Similarly, increasing membrane hyperpolarization from -30 to $-70 \mathrm{mV}$ also produced a downward shift in the channel amplitude histograms, which were well fit by the theoretical $\beta$-distributions (Fig. 6A). Over this membrane potential range, 

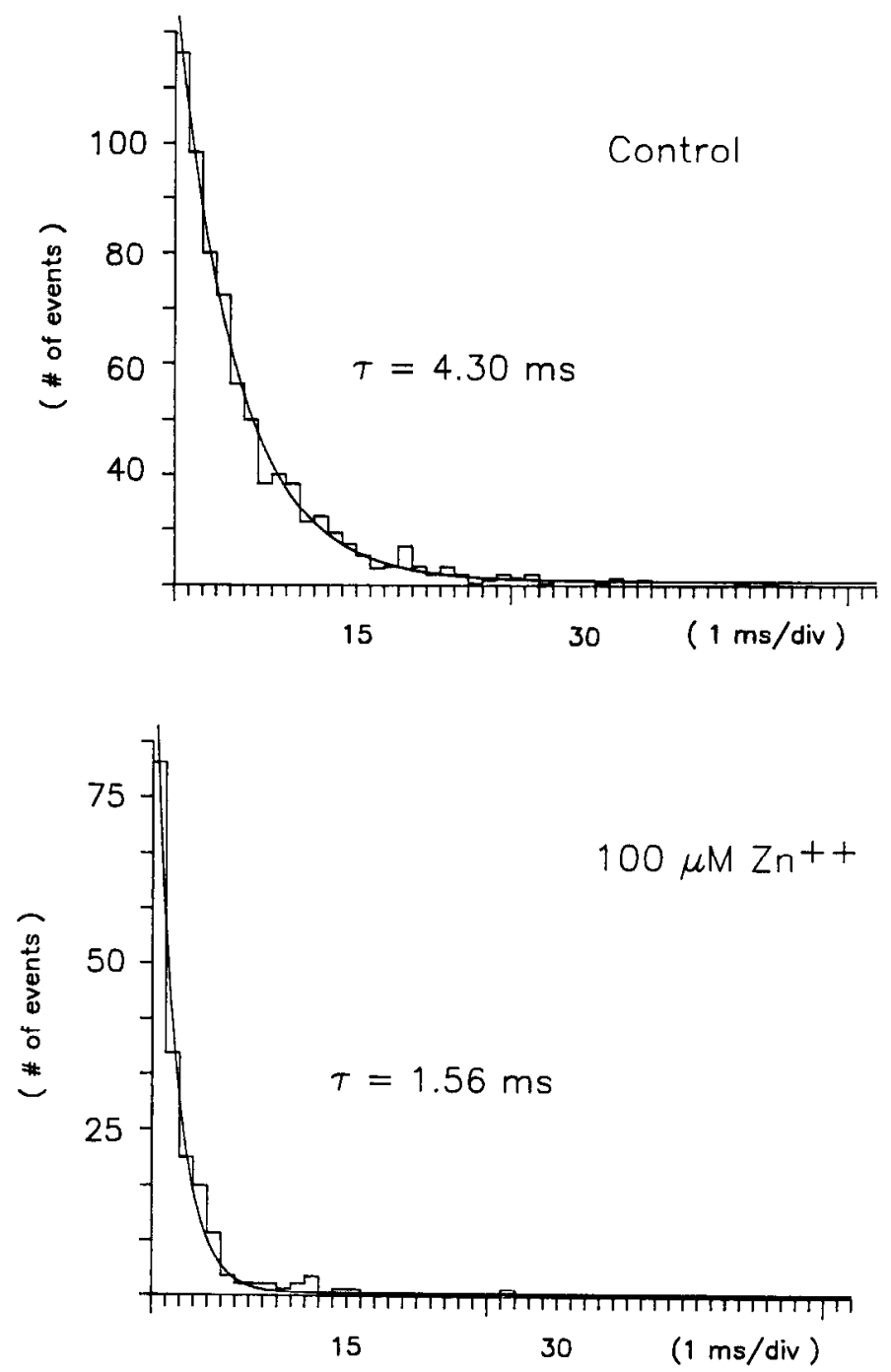

Figure 8. Effect of $\mathrm{Zn}^{2+}$ on mean channel burst duration. Open-time histograms were prepared from a single recording where the patch (held at $-50 \mathrm{mV}$ ) was first exposed to a control solution with $3 \mu \mathrm{M}$ glutamate

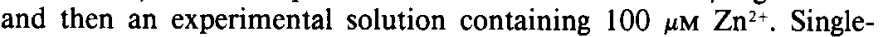
exponential fit to the control histogram (1078 events) gives $\tau=4.3 \mathrm{msec}$

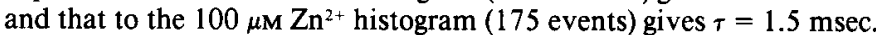
Intermediate concentrations of $\mathrm{Zn}^{2+}$ produced a graded effect on mean channel burst duration; $1 \mu \mathrm{M} \mathrm{Zn^{2+ }}$ gave $\tau=4.1 \mathrm{msec}, 10 \mu \mathrm{M} \mathrm{Zn^{2+ }}$ gave $\tau=3.2 \mathrm{msec}$.

the on rate constant increased from $1.5 \times 10^{8}$ to $5.9 \times 10^{8} \mathrm{M}^{-1}$ $\mathrm{sec}^{-1}$, while the off rate constant remained steady at about 2.8 $\times 10^{4} \mathrm{sec}^{-1}$ (Fig. 6B). The voltage dependence of the on rate constant line fitted by regression would account for a $\delta$ of 0.54 in Equation 1 above. A plot of $K_{d}$ (not shown) yielded a value of $990 \mu \mathrm{M}$ by extrapolation to $0 \mathrm{mV}$, which agrees with the value of $909 \mu \mathrm{M}$ calculated from the Woodhull model (Fig. $4 B$ ). Thus, the voltage dependence of the $\mathrm{Zn}^{2+}$ block is fully accounted for by the voltage dependence of the forward blocking reaction.

The next experiments were designed to characterize the ability of $\mathrm{Zn}^{2+}$ to reduce channel opening. First, quantitative examination of the ability of $\mathrm{Zn}^{2+}$ to reduce channel open probability $\left(P_{\mathrm{o}}\right)$ revealed a potent, concentration-dependent action (Fig. 7). Only about $3 \mu \mathrm{M} \mathrm{Zn}^{2+}$ was needed to reduce $P_{\circ}$ by half. $\mathrm{Mg}^{2+}$ shared this effect with $\mathrm{Zn}^{2+}$ but was about 100 times less potent.
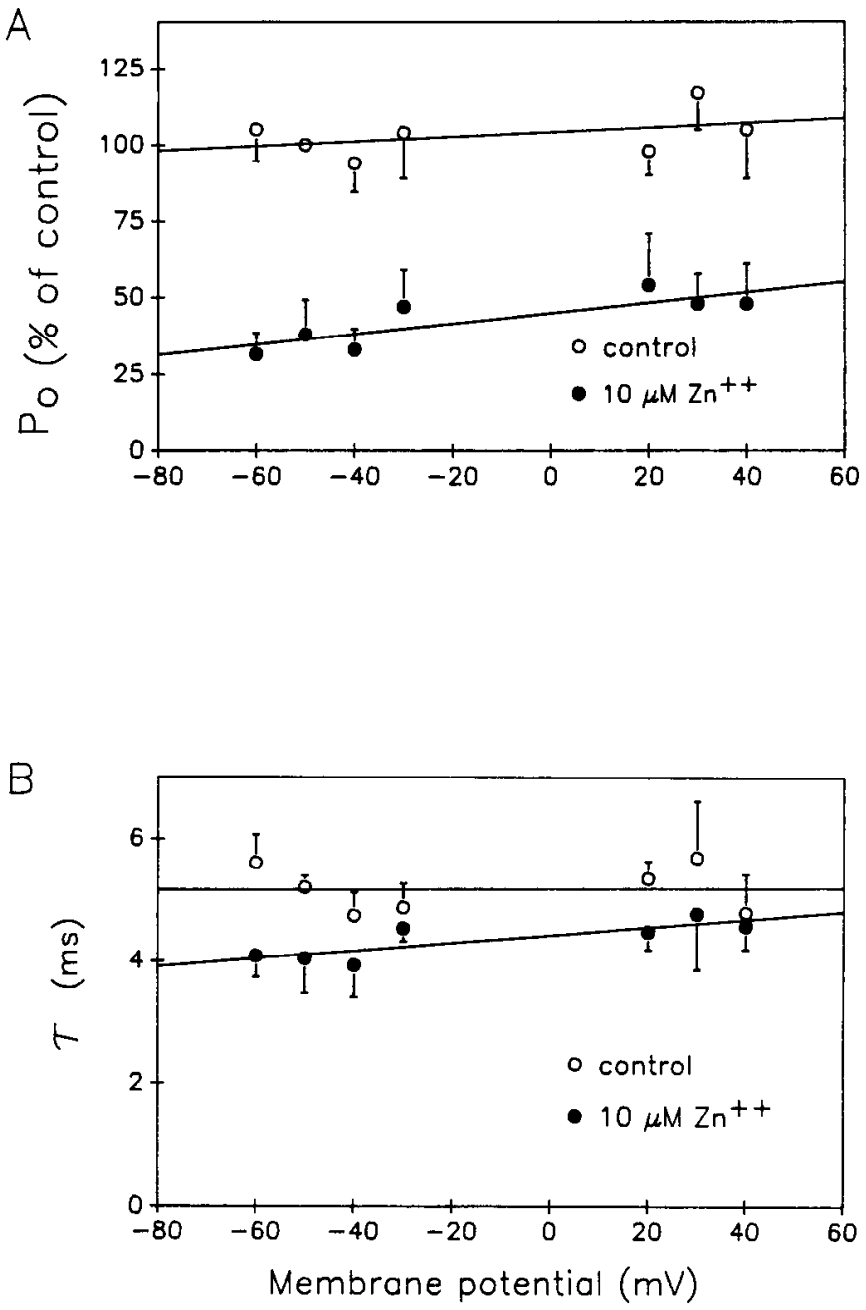

Figure 9. Voltage independence of $\mathrm{Zn}^{2+}$ effect on channel open probability and mean channel burst duration. $A$, Open probability $P_{\circ}$ as a

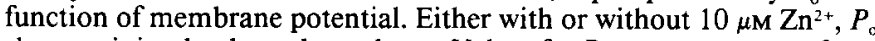
shows minimal voltage dependence. Values for $P_{\mathrm{o}}$ represent means from 4 experiments \pm SEM. Linear regression yields slopes of $0.076 \% / \mathrm{mV}$ for control and $0.13 \% / \mathrm{mV}$ for $10 \mu \mathrm{M} \mathrm{Zn}^{2+}$. $B$, Mean channel open time or burst duration, $\tau$, as a function of membrane potential. Either with or without $\mathrm{Zn}^{2+}, \tau$ shows minimal voltage dependence. Each value for $\tau$ represent the mean of 3 experiments \pm SEM. Linear regression through the data yields slopes of $0.0003 \mathrm{msec} / \mathrm{mV}$ for control and $0.006 \mathrm{msec} /$

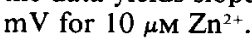

When there is only one active channel, open probability can be broken down as follows:

$$
P_{\mathrm{o}}=f_{\mathrm{o}} \tau
$$

where $f_{\mathrm{o}}$ is the opening frequency and $\tau$ is the mean channel open time. Therefore, a reduction in $P_{\mathrm{o}}$ could be due to a reduction in opening frequency, $f_{\mathrm{o}}$, or a reduction in mean channel open time, $\tau$. The effect of $\mathrm{Zn}^{2+}$ on $P_{\text {o }}$ was largely accounted for by reduction in $f_{\mathrm{o}}$, for $\mathrm{Zn}^{2+}$ concentrations below $10 \mu \mathrm{M}$ (Fig. 7). Above $10 \mu \mathrm{M}, P_{\mathrm{o}}$ was reduced further than $f_{\mathrm{o}}$, suggesting the existence of a concurrent reduction in $\tau$ (Fig. 7). This was confirmed by direct examination of open-time histograms; for example in one experiment, $100 \mu \mathrm{M} \mathrm{Zn}^{2+}$ reduced $\tau$ from 4.30 to $1.56 \mathrm{msec}$ (Fig. 8). These open-time histograms were constructed from data filtered at $1 \mathrm{kHz}$; since brief interruptions in channcl current were not resolved, the estimate of $\tau$ in the presence 
of $\mathrm{Zn}^{2+}$ is best considered to reflect the burst duration of the channel.

Neither the effect of $\mathrm{Zn}^{2+}$ on $P_{\mathrm{o}}$ (Fig. 9A) nor the effect of $\mathrm{Zn}^{2+}$ on $\tau$ (Fig. $9 B$ ) showed much voltage dependence. For these voltage studies, $P_{\text {o }}$ was studied rather than $f_{0}$ because the latter is confounded by reduced signal to noise resolution at depolarized membrane potentials.

\section{Discussion}

The channels studied here in outside-out membrane patches removed from murine neocortical neurons appear similar to those described in previous studies of NMDA receptor-activated channels on central neurons. Others have found NMDA channels to be selectively activated by low micromolar concentrations of glutamate (Nowak et al., 1984; Jahr and Stevens, 1987; Cull-Candy and Usowicz, 1987), to have a main conductance state of $50 \mathrm{pS}$, and to be blocked in a voltage-dependent fashion by $\mathrm{Mg}^{2+}$ (Nowak et al., 1984; Ascher and Nowak, 1988).

The central finding of the present study is that $1-100 \mu \mathrm{M} \mathrm{Zn^{2+ }}$ could powerfully attenuate these NMDA channel currents, consistent with previous cell-level experiments showing that the same concentrations of $\mathrm{Zn}^{2+}$ could selectively block NMDAinduced neuroexcitation (Peters et al., 1987; Westbrook and Mayer, 1987) or neurotoxicity (Peters et al., 1987; Koh and Choi, 1988). Three main effects of $\mathrm{Zn}^{2+}$ were observed: (1) an apparent increase in patch seal resistance; (2) a reduction in channel open probability, for the most part due to reduction in channel opening frequency; and (3) a voltage-dependent reduction in apparent channel amplitude, most likely due to interruptions of channel current too rapid to be resolved by the recording techniques employed.

\section{Zinc increases apparent patch resistance}

$\mathrm{Zn}^{2+}$ consistently decreased baseline pipette current, evident as a steady upward shift in the patch current record. The effect was $\mathrm{Zn}^{2+}$ concentration dependent and increased with membrane hyperpolarization. It varied in magnitude from patch to patch, was not dependent on the presence of NMDA channel activity, and was not mimicked by equimolar $\mathrm{Mg}^{2+}$. Its basis remains to be defined. One possible explanation is an interaction of $\mathrm{Zn}^{2+}$ with charged moieties in the membrane or the pipette glass surface, leading to a stabilizing action on the glass/membrane interface (see Corey and Stevens, 1983). Another possibility might be a reduction of streaming potential currents between the pipette and the membrane. Alternatively, it is possible that $\mathrm{Zn}^{2+}$ might produce a progressive blockade of unresolved small membrane channels, leading to an increase in average membrane resistance. In any case, the baseline shift induced by a given concentration of $\mathrm{Zn}^{2+}$ was relatively stable and did not interfere with the analysis of NMDA channels.

\section{Zinc reduces $N M D A$ channel open probability}

$\mathrm{Zn}^{2+}$ reduced the probability of opening of NMDA channels, largely due to a reduction in the frequency of channel opening. At a membrane potential of $-50 \mathrm{mV}, 3 \mu \mathrm{M} \mathrm{Zn^{2+ }}$ reduccd both open probability and channel opening frequency by about $50 \%$. This potent effect was probably not explained by reduction of free agonist concentration secondary to metal ion complex formation since the concentration of applied glutamate and glycine was increased to compensate for complexing according to published stability constants (Perrin, 1986). Such a correction assumes than $\mathrm{Zn}^{2+}$-glutamate complexes are unavailable to acti- vate the NMDA receptor. If this assumption is incorrect, then the actual reduction of opening frequency by $\mathrm{Zn}^{2+}$ would be even higher.

Another possible explanation for the ability of $\mathrm{Zn}^{2+}$ to reduce channel-opening frequency would be competitive antagonism at the agonist-recognition site. However, $1 \mathrm{mM} \mathrm{Zn}^{2+}$ was observed to reduce ${ }^{3} \mathrm{H}$-glutamate binding to rat synaptic plasma membranes to only $76 \%$ of control (Monahan and Michel, 1987), and it is possible that some of this reduction might be explained by the formation of $\mathrm{Zn}$-glutamate complexes. Also, to the extent that reduction of channel openings is a major component of $\mathrm{Zn}^{2+}$ antagonism of NMDA receptor-activated currents, simple competition with agonist-receptor binding would be inconsistent with the observations that $\mathrm{Zn}^{2+}$ block of neuroexcitation (Peters et al., 1987; Westbrook and Mayer, 1987) and neurotoxicity (Koh and Choi, 1988) persists in the face of high agonist concentrations.

More likely, $\mathrm{Zn}^{2+}$ interacts with the NMDA receptor-channel complex to reduce the coupling between agonist binding and channel gating or to enhance desensitization of the NMDA receptor (Mayer et al., 1989). The observation that the effect of $\mathrm{Zn}^{2+}$ on open probability was largely voltage-independent suggests that it may result from the binding of $\mathrm{Zn}^{2+}$ to a relatively superficial site on the NMDA receptor-channel complex. Reduction of opening frequency is not unique to $\mathrm{Zn}^{2+}$; Nowak et al. (1984) discovered that $\mathrm{Mg}^{2+}$ also reduced NMDA channel opening. However, we found $\mathrm{Mg}^{2+}$ was much weaker in this regard than $\mathrm{Zn}^{2+}$. The ability of low micromolar concentrations of $\mathrm{Zn}^{2+}$ to reduce NMDA channel-opening frequency in a voltage-independent fashion probably accounts for the finding that $5 \mu \mathrm{M} \mathrm{Zn}{ }^{2+}$ could reduce NMDA-induced whole-cell currents in hippocampal neurons even at positive membrane potentials (Westbrook and Mayer, 1987). On the other hand, prior observations suggesting some voltage dependence to $\mathrm{Zn}^{2+}$ block of NMDA-induced neuronal responses at negative membrane potentials (Peters et al., 1987, figure 3C; Westbrook and Mayer, 1987 , figure 3A) probably reflect the superposition of a contribution from the voltage-dependent channel block discussed below.

In addition to reducing channel-opening frequency, higher concentrations of $\mathrm{Zn}^{2+}(>10 \mu \mathrm{M})$ produced a reduction in burst duration, also with little sensitivity to membrane voltage (Fig. 9). The channel open time observed here in the absence of $\mathrm{Zn}^{2+}$, $5.2 \mathrm{msec}$, is similar to the $5.8 \mathrm{msec}$ observed by Ascher et al. (1988) on murine central neurons.

\section{Zinc reduces single-channel amplitude}

At negative membrane potentials, $\mathrm{Zn}^{2+}$ also reduced singlechannel amplitude. This voltage-dependent reduction was $\mathrm{Zn}^{2+}$ concentration dependent between $1-100 \mu \mathrm{M}$. The smoothly progressive nature of the reduction with increasing $\mathrm{Zn}^{2+}$ concentration argues against the idea that $\mathrm{Zn}^{2+}$ potentiates a lower conductance state of the NMDA channel while simultaneously curtailing the activity of the full conductance state (Mayer et al., 1988). Another possible mechanism for the observed reduction in channel amplitude is that $\mathrm{Zn}^{2+}$ might screen a negative surface potential near the channel entrance, thereby reducing cation access to the channel. Indeed, Ascher and Nowak (1988) have postulated such a surface potential screening mechanism to account for the shift of the outward current-voltage relation produced by high concentrations of extracellular $\mathrm{Ca}^{2+}$. However, while the progressive reduction of single-channel cur- 
rent seen with $\mathrm{Zn}^{2+}$ is consistent with surface potential screening, $\mathrm{Zn}^{2+}$ did not produce the predicted shift in the outward currentvoltage relation. Furthermore, the observed increase in singlechannel noise, as well as the much higher potency of $\mathrm{Zn}^{2+}$ over $\mathrm{Ca}^{2+}$ (nearly 1000 -fold at $-50 \mathrm{mV}$ ) are difficult to reconcile with a simple surface-potential model. Instead, as discussed earlier, present observations better fit the hypothesis that $\mathrm{Zn}^{2+}$ causes very brief interruptions of current through the channel.

Supporting this flicker hypothesis was the finding that the effect of $\mathrm{Zn}^{2+}$ on channel-amplitude histograms could be closely approximated by theoretical $\beta$-distributions predicted by a simple model of open-channel block. In particular, the model's prediction that only the block on rate would vary with changes in $\mathrm{Zn}^{2+}$ concentration was consistent with experimental data. The additional finding that the voltage dependence of the on rate was sufficient to account entirely for the voltage dependence of the overall block was in line with rate constant data derived from dwell-time analysis of the $\mathrm{Mg}^{2+}$ block, which suggested greater voltage dependence of the on rate $(e$-fold $/ 17 \mathrm{mV}$ of hyperpolarization) compared with the off rate $(e-$ fold $/ 47 \mathrm{mV}$ of depolarization) (Ascher and Nowak, 1988). Of note, the on and off rate constant values for $\mathrm{Zn}^{2+}$ block are more than an order of magnitude faster than the corresponding values for $\mathbf{M g}^{2+}$ block, consistent with greater experimental difficulty in resolving full channel flicker with $\mathrm{Zn}^{2+}$ compared with $\mathrm{Mg}^{2+}$. Furthermore, at depolarized potentials, $\mathrm{Zn}^{2+}$ may have considerably greater affinity for its channel binding site [calculated $K_{d}(0)=$ $0.9 \mathrm{~mm}]$ than $\mathrm{Mg}^{2+}\left[K_{d}(0)\right.$ calculated by Ascher and Nowak (1988) to be $8.8 \mathrm{~mm}$.

\section{Two sites of action?}

The data collected here are most consistent with the idea that there may be 2 major sites of action for $\mathrm{Zn}^{2+}$ on the NMDA receptor-channel complex, distinguishable by differences in effect on channel currents, required $\mathrm{Zn}^{2+}$ concentration, and voltage dependence (Fig. 10). We recognize that other models can be considered.

One major site of action may be a high-affinity, voltage-independent binding site near the external membrane surface, responsible for reducing channel-opening frequency. This site could modulate receptor-channel interaction or could gate the channel from a very superficial channel site. Certain other divalent cations also may be able to interact to varying degrees with this voltage-independent site. For example, $\mathrm{Cd}^{2+}$ reduces whole-cell currents in a voltage-insensitive manner (Mayer and Westbrook, 1987), and binding studies have shown that both $\mathrm{Cd}^{2+}$ and $\mathrm{Zn}^{2+}$ decrease the association and dissociation rates of ${ }^{3} \mathrm{H}-\mathrm{MK}-801$ (Reynolds and Miller, 1988). The effect of $\mathrm{Zn}^{2+}$ to reduce channel burst duration could be mediated by the same binding site as reduction in opening frequency or by yet another binding site.

The second major site may be a lower-affinity, voltage-dependent site within the NMDA channel itself, responsible for a rapid flicker block of the open channel. The voltage dependence of this site is characterized by a $\delta$ of 0.51 , which suggests that it senses approximately half the transmembrane potential field, and thus may be distinct from the voltage-dependent $\mathrm{Mg}^{2+}$ site, which senses most of the transmembrane field $(\delta \approx 1)$ (Ascher and Nowak, 1988). It is reasonable to postulate that the channel $\mathrm{Zn}^{2+}$ site is superficial to the channel $\mathrm{Mg}^{2+}$ site, although unknown factors such as interactions with other ions within the channel pore preclude simple translation of apparent $\delta$ into a

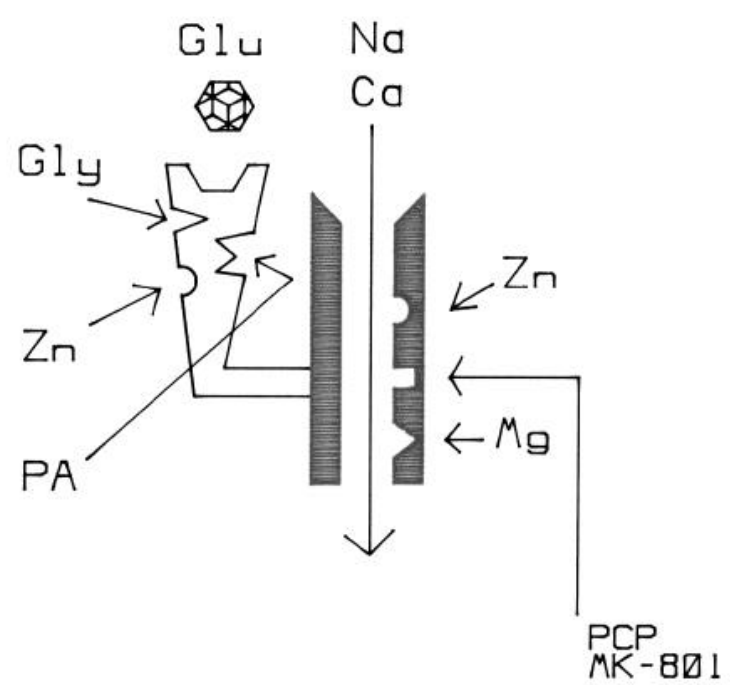

Figure 10. Model for $\mathrm{Zn}^{2+}$ action on the NMDA receptor-channel complex. Speculative model shows 2 sites of action, one influencing the coupling of the NMDA receptor to its channel and the other within the channel itself, perhaps shallow to the $\mathrm{Mg}^{2+}$ site. Some of the $\mathrm{Zn}^{2+}$ released by presynaptic terminals might permeate the open NMDA channel, perhaps triggering changes in the postsynaptic cell. The PCP site is illustrated as a separate site for convenience; it could be the same as the $\mathrm{Zn}^{2+}$ or the $\mathrm{Mg}^{2+}$ site. Modulatory sites for glycine (Johnson and Ascher, 1987) and for polyamines (Ransom and Stec, 1988) are also included.

physical location within the channel (Ascher and Nowak, 1988). The exact relationships between the $\mathrm{Zn}^{2+}$ site, the $\mathrm{Mg}^{2+}$ site, and the phencyclidine (PCP) site within the NMDA channel will require further studies for clarification. MacDonald et al. (1987) found that ketamine had an apparent $\delta$ of 0.53 , while our calculations from the data published by Huettner and Bean (1988) suggest that the PCP ligand MK- 801 could have a steeper voltage dependence, with $\delta$ near 1 .

Beyond its intrinsic significance as an antagonist of NMDA receptor-activated currents, we speculate that the interaction of $\mathrm{Zn}^{2+}$ with a site in the NMDA channel might herald a subsequent event of potential physiological importance-the permeation of $\mathrm{Zn}^{2+}$ through the channel. Ascher and Nowak (1988) as well as Mayer and Westbrook (1987) have discussed the correlation between a divalent cation's rate constant for substitution of the inner sphere of $\mathrm{H}_{2} \mathrm{O}$ (Diebler et al., 1969) and its permeability through the NMDA channel. Fast permeators of the NMDA channel, such as $\mathrm{Ca}^{2+}, \mathrm{Sr}^{2+}$, and $\mathrm{Ba}^{2+}$ exchange their water shells nearly 1000 times faster than voltage-dependent blockers, $\mathrm{Co}^{2+}$ and $\mathrm{Mg}^{2+}$. Interestingly, rates for both $\mathrm{Zn}^{2+}$ and $\mathrm{Mn}^{2+}$ fall between those of fast permeators and the blockers. $\mathrm{Zn}^{2+}$ exchanges its inner hydration shell more than 100 times faster than $\mathbf{M g}^{2+}$ and about 10 times faster than $\mathrm{Mn}^{2+}$. Since $20 \mathrm{mM} \mathrm{Mn}{ }^{2+}$ may carry an inward current (Mayer and Westbrook, 1987), it does not seem unreasonable to suppose that $\mathrm{Zn}^{2+}$ might permeate the channel. Indeed, permeation of a $\mathrm{Zn}^{2+}$ ion through the channel, followed by replacement of the channel block by another $\mathrm{Zn}^{2+}$ ion, could be the molecular substrate for rapid flicker block.

$\mathrm{Zn}^{2+}$ is capable of interacting with many biological molecules; it is intriguing to imagine that the $\mathrm{Zn}^{2+}$ released from neuronal presynaptic terminals might be a "transsynaptic messenger," entering postsynaptic neurons through NMDA channels and triggering metabolic alterations (Weiss et al., 1989). The neu- 
rotoxicity produced by intense $\mathrm{Zn}^{2+}$ exposure (Choi et al., 1988) could be in part due to such $\mathrm{Zn}^{2+}$ entry, as it is competitively attenuated by MK-801 (Choi and Koh, 1988).

\section{References}

Aniksztcjn, L., G. Charton, and Y. Ben-Ari (1987) Sclective relcase of endogenous zinc from the hippocampal mossy fibers in situ. Brain Res. 404: 58-64.

Ascher, P., and L. Nowak (1988) The role of divalent cations in the $\mathrm{N}$-methyl-D-aspartate responses of mouse central neurones in culture. J. Physiol. (Lond.) 399: 247-266.

Ascher, P., P. Bregestovski, and L. Nowak (1988) N-Methyl-D-aspartate-activated channels of mouse central neurones in magnesiumfree solutions. J. Physiol. (Lond.) 339: 207-226.

Assaf, S. Y., and S. H. Chung (1984) Release of endogenous $\mathrm{Zn}^{2+}$ from brain tissue during activity. Nature 308: 734-736.

Choi, D. W., M. A. Maulucci-Gedde, and A. R. Kriegstein (1987) Glutamate neurotoxicity in cortical cell culture. J. Neurosci. 7: 357368.

Choi, D. W., M. Yokoyama, and J. Koh (1988) Zinc ncurotoxicity in cortical cell culture. Neuroscience 24: 67-79.

Choi, D. W., and J. Koh (1988) Zinc central neurotoxicity may require open NMDA channels. Soc. Neurosci. Abstr. 14: 417.

Christine, C. W., and D. W. Choi (1988) Zinc alters NMDA receptormediated channel events on cortical neurons. Neurology 38: $274-$ 275.

Christine, C. W., and D. W. Choi (1989) Effect of zinc on NMDA receptor-mediated channel currents: Two sites of action? Neurology 39: 387.

Corey, D. P., and C. F. Stevens (1983) Science and technology of patch-recording electrodes. In Single Channel Recording, B. Sakmann and E. Neher, eds., pp. 58-59, Plenum Press, New York.

Cull-Candy, S. G., and M. M. Usowicz (1987) Multiple-conductance channels activated by excitatory amino acids in cerebellar neurons. Nature 325: 525-528.

Danscher, G., G. Howell, J. Perez-Clausell, and N. Hertel (1985) The dithizone, Timm's sulphide silver and the selenium methods demonstrate a chelatable pool of zinc in CNS. A proton activation (PIXE) analysis of carbon tetrachloride extracts from rat brains and spinal cords intravitally treated with dithizone. Histochemistry 83: 419422.

Diebler, H., M. Eigen, G. Ilgenfritz, G. Maass, and R. Winkler (1969) Kinetics and mechanism of reactions of main group metal ions with biological carriers. Pure Appl. Chem. 20: 93-115.

FitzHugh, R. (1983) Statistical properties of the asymmetric random telegraph signal, with applications to single-channel analysis. Math. Biosci. 64: 75-89.

Forsythe, I. D., G. L. Westbrook, and M. L. Mayer (1988) modulation of excitatory synaptic transmission by glycine and zinc in cultures of mouse hippocampal neurons. J. Neurosci. 8: 3733-3741.

Frederickson, C. J., M. A. Klitenick, W. I. Manton, and J. B. Kirkpatrick (1983) Cytoarchitectonic distribution of zinc in the hippocampus of man and the rat. Brain Res. 273: 335-339.

Hamill, O. P., A. Marty, E. Neher, B. Sakmann, and F. J. Sigworth (1981) Improved patch-clamp techniques for high resolution current recording from cells and cell free membrane patches. Pfluegers Arch. 391: $85-100$.

Howell, G. A., Welch, M. G., and C. J. Frederickson (1984) Stimu- lation-induced uptake and release of zinc in hippocampal slices. Nature 308: 736-738.

Huettner, J. E., and B. P. Bean (1988) Block of NMDA-activated current by the anticonvulsant MK-801: Selective binding to open channels. Proc. Natl. Acad. Sci. USA 85: 1307-1311.

Jahr, C. E., and C. F. Stevens (1987) Glutamate activates multiple single channel conductances in hippocampal neurones. Nature 325 : 522-525.

Johnson, J. W., and P. Ascher (1987) Glycine potentiates the NMDA response in cultured mouse brain neurons. Nature 325: 529-531.

Koh, J., and D. W. Choi (1988) Zinc alters excitatory amino acid neurotoxicity on cortical neurons. J. Neurosci. 8: 2164-2171.

MacDonald, J. F., Z. Miljkovic, and P. Pennefather (1987) Use-dependent block of excitatory amino acid currents in cultured neurons by ketamine. J. Neurophysiol. 58: 251-266.

Maske, H. (1955) Über den topochemishen Nachweis von Zink im Ammonshorn verschiedener Säugetiere. Naturwissenschaften 42: 424 431.

Mayer, M. L., and G. L. Westbrook (1987) Permeation and block of $\mathrm{N}$-methyl-D-aspartatic acid receptor channels by divalent cations in mouse cultured central neurones. J. Physiol. (Lond.) 394: 501-527.

Mayer, M. L., G. L. Westbrook, and L. Vyklicky (1988) Sites of antagonist action on $\mathrm{N}$-methyl-d-aspartic acid receptors studied using fluctuation analysis and a rapid perfusion technique. J. Neurophysiol. 60: 645-663.

Mayer, M. L., L. Vyklicky, and J. Clements (1989) Regulation of NMDA receptor desensitization in mouse hippocampal neurons by glycine. Nature 338: 425-427.

Monahan, J. B., and J. Michel (1987) Identification and characterization of an $\mathrm{N}$-methyl-d-aspartate-specific $\mathrm{L}[3 \mathrm{H}]$ glutamate recognition site in synaptic plasma membranes. J. Neurochem. 48: 1699-1708.

Neher, E., and J. H. Steinbach (1978) Local anaesthetics transiently block currents through single acetylcholine-receptor channels. J. Physiol. (Lond.) 277: 153-176.

Nowak, L., P. Bregestovski, P. Ascher, A. Herbet, and A. Prochiantz (1984) Magnesium gates glutamate-activated channels in mouse central neurones. Nature 307: 462-465.

Perrin, D. (1986) Stability constants for metal complexes. In Data for Biochemical Research, R. M. Dawson, D. C. Elliott, W. C. Elliott, and K. M. Jones, eds., pp. 399-409, Clarendon Press, Oxford.

Peters, S., J. Koh, and D. W. Choi (1987) Zinc selectively blocks the action of N-methyl-D-aspartate on cortical neurons. Science 236: 589-593.

Ransom, R. W., and N. L. Stec (1988) Cooperative modulation of $\left[{ }^{3} \mathrm{H}\right] \mathrm{MK}-801$ binding to the N-methyl-D-aspartate receptor-ion channel complex by L-glutamate, glycine and polyamines. J. Neurochem. 51: 830-836.

Reynolds, I. J., and R. J. Miller (1988) Multiple sites for the regulation of the N-methyl-D-aspartate receptor. Mol. Pharmacol. 33: 581-584.

Wciss, J. H., J. Koh, C. W. Christine, and D. W. Choi (1989) Zinc and LTP. Nature 338: 212.

Westbrook, G. L., and M. L. Mayer (1987) Micromolar concentrations of $\mathrm{Zn}^{2+}$ antagonize NMDA and GABA responses of hippocampal neurons. Nature 328: 640-643.

Woodhull, A. M. (1973) Ionic blockage of sodium channels in nerve. J. Gen. Physiol. 61: 687-708.

Yellen, G. (1982) Single $\mathrm{Ca}^{2+}$-activated nonselective cation channels in neuroblastoma. Nature 296: 357-359.

Yellen, G. (1984) Ionic permeation and blockage in $\mathrm{Ca}^{++}$-activated $\mathrm{K}$ channels of bovine chromaffin cells. J. Gen. Physiol. 84: 157-186. 